\title{
Prompting the clinical care of non-insulin dependent (type II) diabetic patients in an inner city area: one model of community care
}

\author{
Brian Hurwitz, Caroline Goodman, John Yudkin
}

\begin{abstract}
Objective-To evaluate the effectiveness and acceptability of centrally organised prompting for coordinating community care of non-insulin dependent diabetic patients.

Design-Randomised single centre trial. Patients allocated to prompted care in the community or to continued attendance at hospital diabetic clinic (controls). Median follow up two years.

Setting-Two hospital outpatient clinics, 38 general practices, and 11 optometrists in the catchment area of a district general hospital in Islington.

Patients-181 patients attending hospital outpatient clinics.

Null hypothesis-There is no difference in process of medical care measures and medical outcome between prompted community care and hospital clinic care.
\end{abstract}

Results -14 hospital patients failed to receive a single review in the clinic as compared with three patients in the prompted group $\left(\chi^{2}=6 \cdot 1, \mathrm{df}=1\right.$; $p=0.013)$. Follow up for retinal screening was better in prompted patients than in controls; two prompted patients defaulted as against 12 controls $\left(\chi^{2}=6.9\right.$, $\mathrm{df}=1 ; \mathrm{p}=0.008$ ). Three measures per patient yearly were more frequent.in prompted patients: tests for albuminuria (median $3.0 v 2.3 ; p=0.03$ ), plasma glucose estimations $(3.1 v 2.5 ; \mathbf{p}=0.003)$, and glycated haemoglobin estimations $(2.4 v 0.9 ; \mathrm{p}<0.001)$. Continuity of care was better in the prompted group (3.2 $v 2.2$ reviews by each doctor seen; $\mathbf{p}<0.001$ ). The study ended with no significant differences between the groups in last recorded random plasma glucose concentration, glycated haemoglobin value, numbers admitted to hospital for a diabetes related reason, and number of deaths. Questionnaires revealed a high level of patient, general practitioner, and optometrist satisfaction.

Conclusions-Six monthly prompting of noninsulin treated diabetic patients for care by inner city general practitioners and by optometrists is effective and acceptable.

\section{Introduction}

In the 1980s several British groups reported on studies which compared the effectiveness of diabetic care provided by general practitioners with care from hospital diabetic clinics. Conclusions ranged from condemnation of general practitioner care as "erratic," of "generally poor standard"' and "less satisfactory than care by the hospital diabetic clinic" to a view that organised general practitioner diabetic care "can achieve a degree of glycaemic control ... equal to that reached by a hospital clinic." ${ }^{\prime 3}$ It seemed that effective care could be provided if it was structured and organised. Many authors felt that the best way to structure diabetic care in general practice was for general practitioners to set up miniclinics ${ }^{4-13}$ in order to create the "protected time" needed for assessment of a complex condition. The general practitioner contract of April 1990 served to encourage the adoption of this model of care.

Despite an active policy of promoting the development of general practitioner diabetic miniclinics in Islington in the 1980s few local practices succeeded in establishing this service. In 1987 a significant number of local doctors expressed an interest in assuming greater responsibility for the clinical care of noninsulin treated patients if review could be scheduled in normal surgery time and provided responsibility for retinal screening was not included. Taking our cue from the Cardiff group's vision of a system which "would recall the patients to see their general practitioner at regular intervals, warn... and request... both clinical information and blood for estimation of glycosylated haemoglobin," we have developed a system for prompting community care of non-insulin dependent (type II) diabetes. High street optometrists perform the necessary eye examinations for these patients. ${ }^{14-19}$

\section{Methods}

The prompting system aims to enable general practitioners to structure diabetic care without setting up miniclinics. It is based on the same clinical guidelines for outpatient care available to all doctors in the diabetic clinics of the district general hospital. These advise annual clinical review, to include measurement of weight and glycaemic control, urinary albumin value, blood pressure, foot examination, examination of visual acuity, and retinoscopy through dilated pupils. Between annual assessments a regular clinical review of the patient should include all these assessments except foot and eye examinations unless specifically indicated.

\section{THE PROMPTING SYSTEM}

The hub of the prompting system is a database which sends requests to patients asking them to provide blood and urine samples for random plasma glucose, glycated haemoglobin, and albumin estimations (fig 1). Samples can be taken by a practice nurse, at a nearby health centre, or at a hospital laboratory, whichever suits the patient. All tests are performed by one district general hospital laboratory. Results are incorporated within personalised medical records which serve as clinical review forms. These are sent to patients with a request to take them along to their general practitioner within 10 days. The prompts for blood and urine tests, followed by general practitioner clinical review, are sent six monthly, with alternate clinical review forms comprising annual review and regular review. Patients not already under the care of a hospital eye clinic also receive an annual 


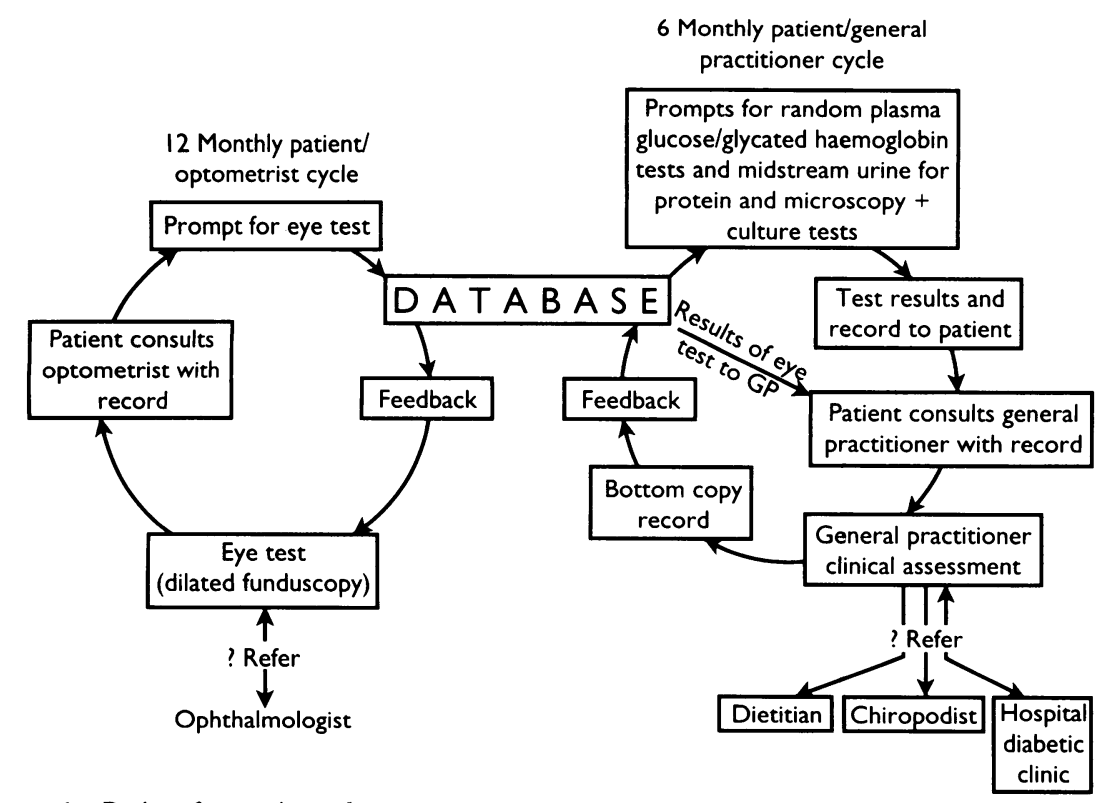

FIG 1-Design of prompting and recall system eye test prompt and a map identifying local optometrists who perform refraction and dilated funduscopy.

The medical and eye review forms include past relevant clinical and biochemical information when known (fig 2). The forms are self copying, and copies completed during clinical assessments are returned to the database to update longitudinal records on each patient. Lack of feedback prompts reminders (see box 1).

\section{PROMPTED CLINICAL ASSESSMENTS}

General practitioner clinical assessments parallel those of the hospital clinic and are performed in the knowledge of each patient's recent and previous random plasma glucose and glycated haemoglobin

\section{Box 1}

\section{Prompting rule set}

(1) Patients receive prompts for blood and urine tests six monthly unless more frequent review is requested by the general practitioner

(2) If the results of blood and urine tests are not received by the database within three weeks of such a prompt a reminder is sent. If there is no response after two such reminders a letter is sent to the general practitioner informing of nonresponse and asking for information. Six months after the initial prompt the next cycle of prompting starts again

(3) The general practitioner review prompt is sent to the patient only when the results of the blood and urine tests have been received by the database. If no copy of the general practitioner review has been received within two weeks of the prompt a telephone call to the general practitioner is made. If it transpires that the patient has not yet attended the general practitioner for this diabetic review one reminder prompt is sent. No response results in the system defaulting to the next prompt six months from the initial blood test prompt

(4) A random plasma glucose concentration between 20.0 and $24.9 \mathrm{mmol} / \mathrm{l}$ results in the patient receiving a general practitioner prompt with a covering letter advising attendance at the general practitioner surgery within three days rather than 10 days

(5) A random plasma glucose concentration $\geqslant 25 \mathrm{mmol} / \mathrm{l}$ results in the database sending an urgent hospital diabetic clinic appointment to the patient rather than a general practitioner review prompt. values. If albuminuria has been detected the result of a midstream urine culture is also included. If the review form referral box is ticked an appointment to attend hospital outpatients is sent to the patient and the database sends a copy of the general practitioner or optometrist review findings to the appropriate hospital clinic doctor who will see the patient in outpatients. In the case of referral to a dietitian or chiropodist the database dispatches brief details to the relevant department. Copies of optometry feedback are sent to the patient's general practitioner, who is thereby kept informed of eye assessments. In this scheme, with the approval of participating general practitioners, optometrists may refer patients directly to a hospital eye clinic by ticking the referral box on the optical review form. Any prompted patient referred to a hospital clinic is assessed in the context of the scheme. Further hospital clinic follow up is arranged only in cases of particular need; otherwise the patient is discharged back to prompted community care.

During the period of the pilot project the prompting system and database were paper driven. They were later computerised by using Revelation software operating within MSDOS on an IBM computer (Revtech UK, Basingstoke, Hampshire).

\section{EVALUATION}

In 1987, with the approval of the local medical and optical committees, Islington general practitioners and optometrists were invited to participate in a pilot prompting project. Thirty eight general practices agreed to take part, including 15 singlehanded and 13 two doctor practices. The general practitioners were sent manuals which explained how prompting would operate, and they attended updating sessions on the management of non-insulin dependent diabetes. A short textbook on diabetic eye disease ${ }^{20}$ was sent to each participating optometrist, who also attended educational meetings at which the importance of dilated funduscopy was emphasised.

A randomised controlled trial comparing prompted care with continuing hospital clinic care was undertaken. As the trial was a comparison of two systems of care the prompted care group subjects could be referred through the system to hospital outpatients, while the hospital clinic group patients could consult their general practitioner for diabetes related reasons. The study aimed to include mobile non-insulin dependent diabetic patients under the age of 80 who had attended the district general hospital diabetic clinics in the previous two years. Patients with the following characteristics were excluded: $(a)$ women of childbearing age; $(b)$ patients with one or more of three established significant diabetic complicationsnamely, nephropathy with creatinine concentration $>150 \mu \mathrm{mol} / \mathrm{l}$ (proteinuria was not in itself an exclusion), ischaemia severe enough to have resulted in gangrene or amputation, and retinopathy worse than background in one eye.

A review of the hospital notes of 570 diabetics registered with the relevant general practitioners identified 415 eligible patients, who were asked in writing for informed consent to enter the trial (fig 3). Of these patients, $215(52 \%)$ agreed to take part, of whom 209 were randomised (by using Cambridge tables of random numbers ${ }^{21}$ ). There were no significant differences in age or sex between patients who consented and those who did not.

A further 28 patients (13 in the prompted group, 15 controls) were excluded from the study. Table I gives the reasons. Randomisation therefore resulted in 89 eligible patients allocated to prompted care and 92 allocated to remain as controls (fig 3).

Prompting began in the prompted group in April 1988 and patients were phased into prompting accord- 


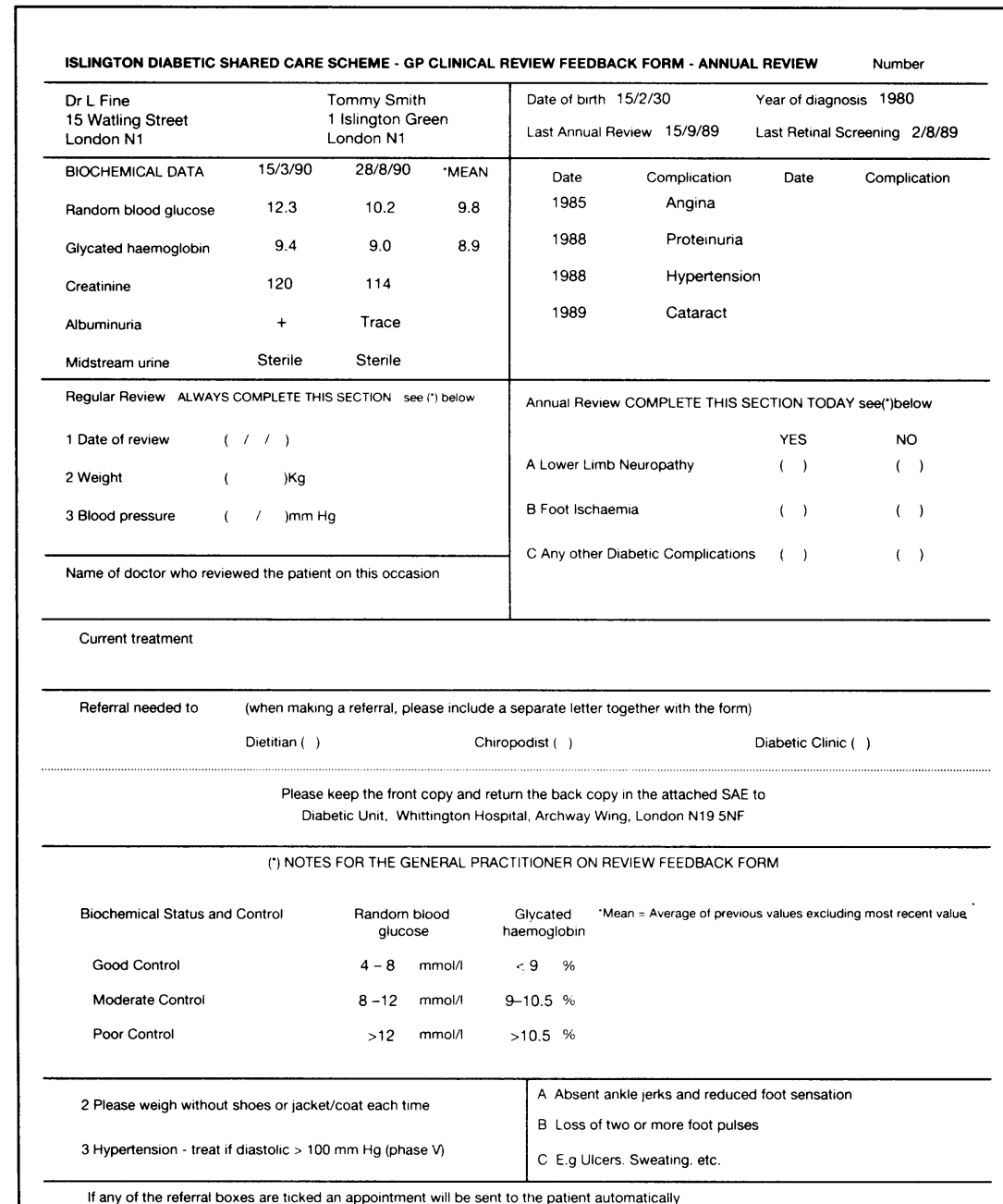

If any of the referral boxes are ticked an appointment will be sent to the patient automatically

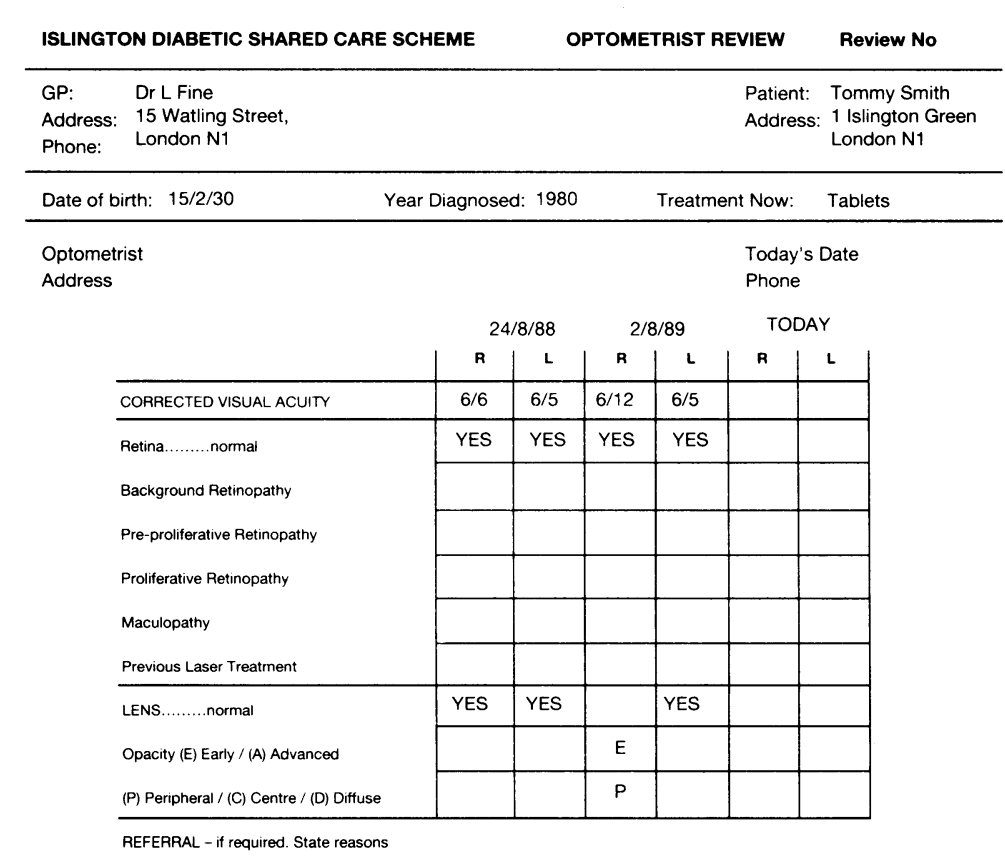

Please detach along perforations and return the bottom copy in the attached SAE to: Diabetic Unit, Whittington Hospital, Archway Wing. London N19 5NF The patient's General Practitioner will be informed of the results of your examination.

FIG 2-General practitioner clinical review feedback form (top) and optometrist review form (bottom) used in Islington diabetic shared care scheme ing to when their next hospital clinic appointment would have been due. The study continued for a total of two years six months (median two years), at the end of which the patients' hospital and general practitioner notes were reviewed together with records of prompted clinical and eye reviews. Information on mortality was obtained from general practitioner notes, hospital information systems, and family health services authority returns on deaths and departed patients.

TABLE I-Reasons for patients found to be ineligible for study after informed consent

\begin{tabular}{lc}
\hline & $\begin{array}{c}\text { No } \\
\text { ineligible }\end{array}$ \\
\hline Not seen in hospital clinic for more than two years at start of study & 17 \\
Withdrew consent before prompting started & 3 \\
Found to be on insulin at start of study & 5 \\
Had significant nephropathy at start of study & 1 \\
Patient had left locality at start of study & 1 \\
Previous hospital notes lost at start of study & 1 \\
\hline Total & 28 \\
\hline
\end{tabular}

A detailed questionnaire was sent to all patients $(n=44)$ who had received 12 months of prompts - that is, five separate prompts - by May 1989 to elicit their views on the acceptability of these arrangements. Questionnaires were also sent to participating general practitioners and optometrists.

\section{Results}

The results are based on an intention to treat analysis. Comparisons of control and prompted patient groups at the start of the study are shown in table II. The groups were well matched for demographic variables and also for most important diabetic attributes, although mean systolic blood pressure was recorded as $9 \mathrm{~mm} \mathrm{Hg}$ greater in the control group $(95 \%$ confidence interval $2 \cdot 1$ to $16.0 \mathrm{~mm} \mathrm{Hg} ; \mathrm{p}=0.011$ ) and 14 patients in the prompted group were documented as having signs of leg ischaemia compared with only four controls $\left(\chi^{2}=5 \cdot 7, \mathrm{df}=1 ; \mathrm{p}=0 \cdot 017\right)$.

\section{PROCESS OF CARE}

During the study period 333 prompts for blood and urine tests generated 296 sets of results, an $89 \%$ completion rate (table III). Of the consequent 296 prompts requesting general practitioner clincial review, 275 were completed $(93 \%$ compliance with general practitioner prompts, $83 \%$ completion rate of both blood tests and general practitioner reviews). Of 145 prompts for eye tests by optometrists, $125(86 \%)$ were completed.

Fourteen $(15 \%)$ of the control group failed to be seen again in a hospital diabetes clinic during the study period compared with only three $(3 \cdot 4 \%)$ of the prompted patients who failed to attend for clinical diabetic review $(p=0.013$; table IV). In those patients who did not default from follow up all the clinical process of care measures were carried out more frequently in the prompted group; for most comparisons the differences were significant. The prompted group also received greater continuity of care, the number of diabetic reviews performed by each participating doctor being significantly greater than in the hospital clinic group $(3 \cdot 2 v 2 \cdot 2$ respectively; $p<0 \cdot 001)$. There was no difference in the number of patients referred for dietary advice or chiropody.

At the end of October 1990, 94\% (170/181) of the general practitioner notes for the study patients were traced. With the exclusion of prompted consultations for diabetic review they disclosed a high annual consultation rate for both groups $(8 \cdot 1$ in the prompted group $v 6.4$ per year in the controls; $\mathrm{p}=\mathrm{NS}$ ). The number of non-prompted, diabetes related con- 
TABLE II - Baseline comparisons at start of study. ${ }^{\star}$ Results represent most recent values for each group before randomisatión. Means are given for normally distributed data, median for skewed data

\begin{tabular}{lccc}
\hline & Control group & Prompted group & p Value \\
\hline Mean age (years) (SD) & $63 \cdot 1(8 \cdot 6)[\mathrm{n}=92]$ & $62 \cdot 0(11 \cdot 2)[\mathrm{n}=89]$ & $\mathrm{NS}$ \\
Mean duration of diabetes mellitus (years) (SD) & $7 \cdot 1(4 \cdot 9)[\mathrm{n}=91]$ & $6 \cdot 9(5 \cdot 0)[\mathrm{n}=89]$ & $\mathrm{NS}$ \\
Median interval between last diabetic clinic & & & \\
$\quad$ attendance and randomisation (years)(range) & $0 \cdot 6(0-2 \cdot 0)[\mathrm{n}=92]$ & $0 \cdot 6(0-1 \cdot 8)[\mathrm{n}=89]$ & $\mathrm{NS}$ \\
No (\%) of male patients & $51 / 92(55)$ & $54 / 89(61)$ & $\mathrm{NS}$ \\
No(\%) of patients controlled by diet alone & $26 / 92(28)$ & $23 / 89(26)$ & $\mathrm{NS}$ \\
No(\%) of patients controlled by diet plus & & & \\
hypoglycaemics & $62 / 92(67)$ & $65 / 89(73)$ & $\mathrm{NS}$ \\
Mean weight $(\mathrm{kg})(\mathrm{SD})$ & $75 \cdot 2(12 \cdot 9)[\mathrm{n}=83]$ & $76 \cdot 1(14 \cdot 5)[\mathrm{n}=85]$ & $\mathrm{NS}$ \\
Mean random plasma glucose (mmol/) (SD) & $9 \cdot 9(4 \cdot 1)[\mathrm{n}=90]$ & $9 \cdot 6(3 \cdot 8)[\mathrm{n}=88]$ & $\mathrm{NS}$ \\
Mean glycated haemoglobin (\%) (SD) & $10 \cdot 3(2 \cdot 3)[\mathrm{n}=41]$ & $10 \cdot 4(2 \cdot 5)[\mathrm{n}=28]$ & $\mathrm{NS}$ \\
Mean systolic blood pressure (mm Hg)(SD) & $153 \cdot 6(24 \cdot 2)[\mathrm{n}=86]$ & $144 \cdot 5(22 \cdot 0)[\mathrm{n}=86]$ & $0 \cdot 011$ \\
Mean diastolic blood pressure (mm Hg)(SD) & $84 \cdot 3(10 \cdot 9)[\mathrm{n}=86]$ & $83 \cdot 3(11 \cdot 5)[\mathrm{n}=86]$ & $\mathrm{NS}$ \\
No(\%) of patients without diabetic complications & $33 / 92(36)$ & $39 / 86(45)$ & $\mathrm{NS}$ \\
No (\%) of patients with ischaemic heart disease & $18 / 92(20)$ & $17 / 86(20)$ & $\mathrm{NS}$ \\
No (\%) of patients with neuropathy & $25 / 92(27)$ & $20 / 86(23)$ & $\mathrm{NS}$ \\
No(\%) of patients with leg ischaemia & $4 / 92(4)$ & $14 / 86(16)$ & $0 \cdot 017$ \\
Mean No of complications per patient (SD) & $1 \cdot 3(1 \cdot 2)[\mathrm{n}=92]$ & $1 \cdot 1(1 \cdot 3)[\mathrm{n}=86]$ & $\mathrm{NS}$
\end{tabular}

*Information on all variables not available for $100 \%$ of each group.

Statistical tests were two tailed $t$ test for continuous variables and $\chi^{2}$ test for proportions (with continuity correction).

\begin{tabular}{|c|c|c|c|}
\hline & $\begin{array}{c}\text { No of } \\
\text { prompts } \\
\text { issued }\end{array}$ & $\begin{array}{l}\text { No of } \\
\text { prompted } \\
\text { actions } \\
\text { completed }\end{array}$ & $\stackrel{\%}{\%} \underset{\text { rate }}{\text { Compliance }}$ \\
\hline $\begin{array}{l}\text { Blood and urine tests }(n=89) \\
\text { General practitioner clinical }\end{array}$ & 333 & 296 & 89 \\
\hline review $(n=89)$ & 296 & 275 & 93 \\
\hline Eye review $(n=74)^{\star}$ & 145 & 125 & 86 \\
\hline
\end{tabular}

TABLE IV-Process of care measures in patients reviewed at least once during study period. Means are given for normally distributed data

\begin{tabular}{|c|c|c|c|}
\hline & Control group & Prompted group & p Value \\
\hline No (\%) of patients without doctor diabetes review & $14 / 92(15 \cdot 2)$ & $3 / 89(3.4)$ & 0.013 \\
\hline $\begin{array}{l}\text { Mean duration of study (years) (SD) for patients with } \\
\text { one or more reviews }\end{array}$ & $2 \cdot 0(0 \cdot 6)$ & & 0.005 \\
\hline Mean No of doctor diabetes reviews per patient per year (SD) & $\begin{array}{c}2 \cdot 0(0.0)[1=70] \\
2 \cdot 4(1 \cdot 3)\end{array}$ & $\begin{array}{l}3 \cdot 0(3 \cdot 8) \\
3 \cdot 8]\end{array}$ & NS \\
\hline Mean No of diabetes reviews per patient per doctor (SD) & $2 \cdot 2(2 \cdot 0)$ & $3 \cdot 2(1 \cdot 9)$ & $<0 \cdot 001$ \\
\hline Mean No of urine tests for albumin per patient per year (SD) & $2 \cdot 3(1 \cdot 4)$ & $3.0(4 \cdot 5)$ & 0.03 \\
\hline $\begin{array}{l}\text { Mean No of plasma glucose estimations per patient } \\
\text { per year (SD) }\end{array}$ & $2 \cdot 3(1 \cdot 4)$ & $3 \cdot 1(4 \cdot 5)$ & 0.003 \\
\hline $\begin{array}{l}\text { Mean No of glycated haemoglobin estimations per } \\
\text { patient per year (SD) }\end{array}$ & $0.9(0.9)$ & $2 \cdot 4(3 \cdot 8)$ & $<0.001$ \\
\hline No (\%) of patients referred to dietitian & $32 / 78(41)$ & $29 / 86(34)$ & NS \\
\hline No $(\%)$ of patients referred to chiropodist & $10 / 78(13)$ & $7 / 86(8)$ & NS \\
\hline
\end{tabular}

Statistical tests were two tailed $t$ test for duration. Mann-Whitney test for rates (adjusted for ties), and $\chi^{2}$ test for proportions (with continuity correction).

TABLE $\mathrm{v}-$ Numbers of structured clinical reviews of diabetes per patient during study period. Values are means $(S D)$

\begin{tabular}{llll}
\hline Place of review & $\begin{array}{c}\text { Control group } \\
(\mathrm{n}=78)\end{array}$ & $\begin{array}{c}\text { Prompted group } \\
(\mathrm{n}=86)\end{array}$ & $\mathrm{p}$ Value \\
\hline $\begin{array}{l}\text { Hospital diabetic clinic } \\
\text { General practice }\end{array}$ & $\begin{array}{l}4 \cdot 2(2 \cdot 7)^{\star} \\
0\end{array}$ & $\begin{array}{l}1 \cdot 6(2 \cdot 2) \\
3 \cdot 2(1 \cdot 7) \dagger\end{array}$ & $\begin{array}{c}<0 \cdot 0001 \\
<0 \cdot 0001\end{array}$ \\
\hline Total & $4 \cdot 2(2 \cdot 7)$ & $4 \cdot 8(2 \cdot 2)$ & NS \\
\hline
\end{tabular}

$\star$ In control group all reviews were done in hospital.

tIn prompted group $67 \%$ of reviews were done in general practice.

TABLE VI-Medical outcome. Results represent values nearest end of study (31 October 1990). Means are given for normally distributed data

\begin{tabular}{|c|c|c|c|}
\hline & Control group & Prompted group & p Value \\
\hline Mean random plasma glucose $(\mathrm{mmol} / \mathrm{l})(\mathrm{SD})$ & $11 \cdot 2(4 \cdot 2)[n=77]$ & $11 \cdot 2(4 \cdot 2)[n=82]$ & NS \\
\hline Mean glycated haemoglobin (\%) (SD) & $10 \cdot 6(2 \cdot 5)[n=81]$ & $10 \cdot 3(2 \cdot 3)[n=85]$ & NS \\
\hline \multicolumn{4}{|l|}{ Mean of each patient's mean glycated haemoglobin since } \\
\hline randomisation (\%) (SD) & $10 \cdot 6(2 \cdot 4)^{\star}$ & $10 \cdot 0(2 \cdot 0) \dagger$ & NS \\
\hline Total No of treatment category changes start to finish & $13(34 \cdot 7)$ & & NS \\
\hline No (\%) of patients switching from diet to oral hypoglycaemics & $8 / 23(35)$ & $10 / 23(43)$ & NS \\
\hline No $(\%)$ of patients switching from diet to insulin & $1 / 23(4)$ & $2 / 23(9)$ & NS \\
\hline No (\%) of patients switching from oral hypoglycaemics to insulin & $4 / 55(7 \cdot 3)$ & $2 / 63(3)$ & NS \\
\hline \multicolumn{4}{|l|}{ No $(\%)$ of patients who received hospital inpatient treatment } \\
\hline Diabetes related & $17 / 92(18)$ & $8 / 89(9)$ & NS \\
\hline Non-diabetes related & $10 / 92(11)$ & $7 / 89(8)$ & NS \\
\hline No $(\%)$ of deaths & $7 / 92(8)$ & $7 / 89(8)$ & NS \\
\hline
\end{tabular}

*Based on 202 observations in 81 controls.

†Based on 296 observations in 85 patients in prompted group.
Statistical tests were two tailed $t$ test for duration, Mann-Whitney test for rates (adjusted for ties), and $\chi^{2}$ test for

proportions (with continuity correction).
Reasons for exclusion

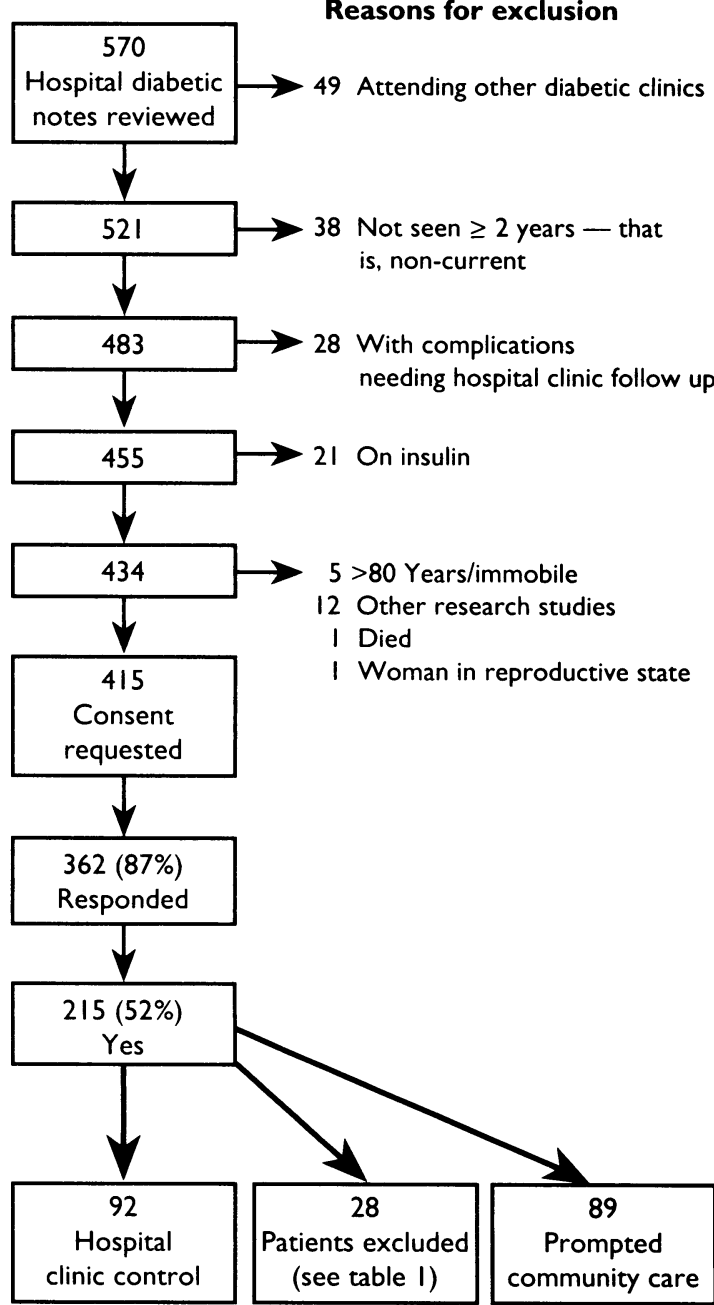

sultations with general practitioners also showed no significant difference between the two groups.

A total of $52(58 \%)$ prompted patients received 139 hospital clinic reviews during the study. Participating general practitioners referred $28(31 \%)$ patients; and the database referred three $(3.4 \%)$ on account of high blood glucose concentrations. Five $(6 \%)$ prompted patients changed their minds about accepting prompting and were subsequently transferred back to hospital outpatients. The remaining $16(18 \%)$ patients were referred by other hospital clinics, after inpatient episodes, or appeared to have referred themselves. The number of structured clinical assessments per patient by location of care for each group is shown in table $\mathrm{V}$. During the study period the frequency of structured review was comparable in the two groups. In the control group all occurred in hospital diabetic clinics whereas for the prompted group 67\% occurred in general practice. When process of care measures were reanalysed after excluding the 21 patients who were referred back to the hospital clinic other than through the prompting system, all process of care measures in table IV remained more frequent in the prompted subgroup ( $n=65$ prompted subjects).

\section{MEDICAL OUTCOME}

By the end of the study there were no differences between the groups in the means of the last recorded random plasma glucose and glycated haemoglobin concentrations, though mean random plasma glucose values had risen from baseline by $1.3 \mathrm{mmol} / \mathrm{l}$ and $1.6 \mathrm{mmol} / \mathrm{l}$ in control and prompted groups respectively (table VI). An additional measure of glycaemic control was provided by looking at the mean of all the 


\section{Box 2}

\section{Patient questionnaire}

\section{Section 3: diabetic review by general practitioner}

Review of your diabetes occurs in general practice soon after you receive the record with the results of blood and urine tests.

(1) In your opinion, does the doctor who usually reviews your diabetes apply the same standard of blood sugar control as the hospital doctor?

$\begin{array}{lcc} & \text { Response (\%) } & \mathrm{n}=39 \\ \text { Yes } & 56 & \\ \text { No } & 10 & \\ \text { Don't know } & 28 & \\ \text { Unanswered } & 5 & \end{array}$

(2) Do you feel that the general practitioner makes a thorough assessment of your diabetes?

Very thorough assessment

Thorough assessment

Adequate assessment

Poor assessment

Very poor assessment

Unanswered

$\begin{array}{cl}\text { Response (\%) } & \mathrm{n}=39 \\ 33 & \\ 23 & \\ 31 & \\ 8 & \\ 0 & \\ 5 & \end{array}$

(3) Do you trust the general practitioner to monitor your diabetes as well as or better than the hospital doctor?

Better than the hospital clinic

As well as the hospital clinic

Worse than the hospital clinic

$\begin{array}{cl}\text { Response }(\%) & \mathrm{n}=39 \\ 8 & \\ 82 & \\ 8 & \\ 3 & \end{array}$

Section 4: community diabetic eye care

Once a year you receive a reminder to have an eye test, together with a map of those optometrists who have a particular interest in diabetic eye problems.

(1) Did the last optometrist to check your eyes for diabetic eye problems put drops in your eyes before examining them?
Yes

No

Don't know

Unanswered

(2) In your opinion, is the eye test by an optometrist:

Better than the eye check up in the hospital clinic? As good as the eye check up in the hospital clinic? Worse than the eye check up in the hospital clinic? Unanswered

$\begin{array}{cl}\text { Response (\%) } & \mathrm{n}=29 \\ 52 & \\ 24 & \\ 24 & \\ 0 & \end{array}$

$\begin{array}{cc}\text { Response }(\%) & \mathrm{n}=29 \\ 31 & \\ 48 & \\ 3 & \\ 17 & \end{array}$

(3) Overall, are these arrangements for your eye check ups in the community:

Very acceptable?

Acceptable?

Unacceptable?

Very unacceptable?

Unanswered compared with 0.9 in the control group (NS). There was no significant difference in the number of patients referred to hospital eye clinics. The number of cataracts newly recorded by optometrists in the prompted group exceeded that recorded by doctors in the hospital clinic group $(29 v 3 ; \mathbf{p}<0.001)$ but there was no difference in the recorded rate of diabetic retinopathy in the two groups.

\section{ACCEPTABILITY}

High compliance levels suggested acceptability of the scheme to all groups involved. More detailed (39/42), and a sample of their responses is shown in box 2 . Thirty two patients ( $82 \%$ ) judged prompted community care, as a whole, to be as good as their former hospital clinic care.

All doctors $(n=48)$ in the participating practices who had performed two or more prompted clinical reviews by May 1989 were also sent a questionnaire of 24 question stems, of which seven are reproduced in box 3; 31 general practitioners $(65 \%)$ responded. Clinical assessments were estimated to take on average 9.8 minutes for a regular review and 13.4 minutes for an annual review. The general practitioners scored this method of care 4.3 on average, on a scale "very poor" (score 1) to "excellent" (score 5). Their confidence in providing care within this framework averaged 4 on the same scale, all but three of the doctors indicating that this method of care interfaced well with their primary health care practice. Despite the absence of a consensus on who had clinical responsibility for the patients in this scheme-general practitioner, hospital, or both -28 of the 31 general practitioners wished to continue providing diabetic care within this framework. Most of the responding general practitioners wanted more of their patients included within the prompting scheme.

The views of participating optometrists were also sought. ${ }^{22}$ Eleven optometrists working in 15 different locations were visited and interviewed with a structured questionnaire. All expressed satisfaction with the working of the prompting scheme and 10 wanted more patients to be included. Besides performing refraction and examinations of the media of each eye all the optometrists reported that they had dilated the pupils of the prompted patients. All had access to a tonometer. All expressed satisfaction with the design of the optometry clinical review form.

\section{Discussion}

This study has shown that with a prompting system diabetic care comparable to that of a hospital diabetic clinic can be provided in small inner city practices, and with a lower lost to follow up rate. Compliance of doctors and patients proved high and the system as a whole was widely acceptable. The lower default rate in the community group is particularly important because loss to follow up carries an increased risk of diabetic complications, especially in non-insulin treated patients. ${ }^{23}$

The approach adopted in Islington could have wide applicability. Of the 570 patients whose hospital notes were reviewed before the study, 415 (73\%) were judged by generally accepted criteria to be medically suitable for community care.

Though process of care measures may be an imperfect guide to the standard of patient care because of differences in the knowledge and skills of health carers in their different settings, we believe that our results are a very considerable improvement on those of previous British studies. In the Cardiff trial $14 \%$ of community care patients received regular general responses were sought by means of questionnaires. The response to the patient questionnaire was $93 \%$ or diabetic retinopathy (table VII). During the stud period 12 controls and two prompted patients did not receive either hospital outpatient eye examination or optometry screening $(p=0 \cdot 008)$. The prompted group received on average $1 \cdot 1$ eye examinations per year 
practitioner review and only 5\% received yearly blood glucose estimations. ${ }^{2}$ In Kirkcaldy only two thirds of patients received a diabetes review by their general practitioner in the first or second year of a two year study and only $50 \%$ had annual blood glucose assessments. ${ }^{24}$ In a non-randomised study in Ipswich among a group of 209 diabetics discharged to general practitioner care with agreed standards of medical follow up

TABLE VII-Baseline process of care for eyes and outcome comparisons. Results represent most recent values for each group before randomisation for baseline comparisons and nearest end of study for outcome comparisons

\begin{tabular}{|c|c|c|c|}
\hline & Control group & Prompted group & p Value \\
\hline \multicolumn{4}{|l|}{ Initial baseline comparisons } \\
\hline $\begin{array}{l}\text { Entire groups: } \\
\text {. }\end{array}$ & $22 / 92(24)$ & $15 / 89(17)$ & NS \\
\hline \multicolumn{4}{|l|}{ Non-hospital eye clinic attenders: } \\
\hline \multicolumn{3}{|l|}{ No (\%) of patients with cataract or past extraction } & NS \\
\hline \multicolumn{3}{|l|}{ No $(\%)$ of patients with non-sight threatening } & NS \\
\hline \multicolumn{4}{|l|}{ Process of care in non-hospital eye clinic attenders } \\
\hline $\begin{array}{l}\text { No }(\%) \text { of non-attenders } \\
\text { Patients who attended. }\end{array}$ & $12 / 70(17)$ & $2 / 74(3)$ & 0.008 \\
\hline \multicolumn{4}{|l|}{ Patients who attended: } \\
\hline \multicolumn{4}{|l|}{$\begin{array}{l}\text { Mean No of eye examinations per patient per year (SD) } \\
\text { No }(\%) \text { of patients referred to hospital eye clinic }\end{array}$} \\
\hline $\begin{array}{l}\text { No (\%) of patients referred to hospital eye clinic } \\
\text { during study }\end{array}$ & $11 / 58(19)$ & $7 / 72(10)$ & NS \\
\hline \multicolumn{4}{|l|}{ Outcome } \\
\hline \multirow{3}{*}{$\begin{array}{l}\text { No (\%) of patients with new cataract or cataract } \\
\text { extraction during study } \\
\text { No (\%) of patients with new non-sight threatening } \\
\text { retinopathy during study } \\
\text { No }(\%) \text { of patients with new sight threatening retinopathy } \\
\text { during study }\end{array}$} & $3 / 58(5)$ & $29 / 72(40)$ & $<0.001$ \\
\hline & $2 / 58(4)$ & $2 / 72(3)$ & NS \\
\hline & $5 / 58(9)$ & $2 / 72(3)$ & NS \\
\hline
\end{tabular}

Statistical tests were Mann-Witney test for rates (adjusted for ties) and $\chi^{2}$ test for proportions (with continuity correction).

\section{Box 3}

\section{General practitioner questionnaire}

(1) Is the prompting system a satisfactory method of organisation for supporting the clinical care of non-insulin dependent diabetic patients in your practice?

$$
\text { Very poor }
$$

\section{Excellent Mean}

Scale

1

Response (\%)

2
10

3

4

5

(2) How confident do you feel about providing clinical care to these patients using this system?

$$
\text { Not at all confident }
$$

Scale

Response (\%)

12

\begin{tabular}{|c|c|c|}
\hline & & $\begin{array}{l}\text { Very } \\
\text { confident }\end{array}$ \\
\hline 3 & 4 & 5 \\
\hline 7 & 48 & 55 \\
\hline
\end{tabular}

2

(3) Are the clinical review forms in use:

$$
\text { Useless? }
$$

Scale

$\begin{array}{cc}1 & 2 \\ \text { Too simple? } & 2 \\ 1 & 2 \\ \text { Provide too } & \text { little space? } \\ 1 & 2\end{array}$

$\begin{array}{cccc} & & \text { Useful? } & \begin{array}{c}\text { Mean } \\ \text { score } \\ 3\end{array} \\ & 4 & 5 & 4 \cdot 0 \\ 3 & 4 & \text { Too complex? } & \\ & 4 & 5 & 2 \cdot 9 \\ 3 & \text { Provide too much space? } & \\ 4 & 4 & 5 & 2 \cdot 9\end{array}$

(4) Does seeing a diabetic patient for clinical review disrupt your surgery to any appreciable extent?

$$
\text { A great deal }
$$

Scale

Response (\%)

$\begin{array}{lr}1 & 2 \\ 0 & 10\end{array}$

3

4
29

$\begin{array}{cc}\text { Not at all } & \begin{array}{c}\text { Mean } \\ \text { score }\end{array} \\ 5 & 4 \cdot 3 \\ 39 & \end{array}$

(5) How long does it take to complete:

An annual review assessment? A regular review assessment? (1 Unanswered)

(6) In the current system who do you feel takes clinical responsibility for these prompted patients?

$\begin{array}{ccccc} & \text { General practitioner } & \text { Hospital } & \text { Both } & \text { Don't know } \\ \text { Response } & 26 \% & 10 \% & 55 \% & 10 \%\end{array}$

(7) Would you be prepared to have more patients attending your surgery for their diabetic care within this framework?

$\begin{array}{cccc} & \text { Yes } & \text { No } & \text { Undecided } \\ \text { Response } & 76 \% & 4 \% & 20 \%\end{array}$

only $25 \%$ of patients had had their urine tested or blood glucose value estimated by their general practitioner in the previous two years. ${ }^{1}$ Prompting in Islington also ensured very high levels of specific diabetes assessments, comparing favourably with the most comprehensive levels of care reported from hospital clinics and from general practitioner miniclinic care. ${ }^{12} 24-26$

\section{NEED FOR EASY AND APPROPRIATE REFERRAL}

A third of all structured diabetes reviews in the prompted group occurred in hospital outpatients but this does not detract from the effectiveness of the prompted care package as a whole. Though 21 of 52 $(40 \%)$ of these referrals were not made by participating general practitioners and a proportion may have constituted unnecessary duplication of care, most were referred appropriately as part of the shared care arrangements. Effective community care must provide a mechanism which allows easy and appropriate referral to and from hospital clinics. Prompted care in Islington successfully supported a shift of two thirds of the burden of care from hospital clinic to community setting over two and a half years.

Mean plasma glucose and glycated haemoglobin values, unlike complication rates, are not subject to observer error and provide useful proxy measures of outcome. Our results are in keeping with findings from Wolverhampton, where in a non-randomised trial of discharge to general practitioner miniclinic care of patients with both insulin treated and non-insulin treated diabetes there was no loss of glycaemic control. They contrast, however, with findings from the Cardiff trial, where the available measures of glycated haemoglobin indicated worse glycaemic control in the community care group at the end of the study, although there were no prerandomisation glycated haemoglobin measurements. ${ }^{2}$ Previous studies have noted a higher mortality in the community group, ${ }^{24}$ but this was not the case in Islington.

Responsibility for retinal screening lay with optometrists unless the patient was already under the care of a hospital eye clinic. After allowing for the much higher non-attendance rate in controls, the annual rate of eye examination per patient and the number of patients referred to a hospital ophthalmic clinic were comparable in the two groups. The larger number of cataracts recorded in the prompted group probably reflects the diligence of optometrists in noting these defects, compared with doctors in the hospital diabetic clinic. It is recognised that without standardisation and training of the optometrists and doctors involved such measures, together with those of recorded retinopathy, are "soft" measures of outcome.

\section{WILLINGNESS OF GPS TO PARTICIPATE}

Despite financial inducements provided by the general practitioner contract and a doubling in the number of nurses working with participating practices in the past two years, few local general practitioners wish to establish miniclinics. General practitioners in Camden and Islington make only half the national annual average of clinic payment claims to the family health services authority. This study has shown that an acceptable standard of diabetic care can be provided in normal surgery time. Structured prompting of community care allows "protected review" in normal surgeries rather than requiring "protected time" in specially designated miniclinics. ${ }^{27} 28$ However, the degree of uncertainty concerning overall clinical responsibility for prompted patients revealed by the general practitioner questionnaire needs to be carefully addressed.

Organisational and clinical guidelines embedded in the Islington prompting system may be varied and developed as standards of good practice evolve or 
as new resources become available locally. ${ }^{29}$ For example, a number of future enhancements are already envisaged involving the inclusion of ideal body weight on the general practitioner review forms and an option for general practitioners to request review by a diabetes education nurse. Requests for intraocular pressure measurement may be added to the optical review forms. In July 1993 payments to general practitioners for disease management clinics will stop completely. In the case of non-insulin treated patients the health care objectives which practices will then have to meet in order to qualify for diabetic care payments could be met by prompting structured care as in Islington. Expansion of this pilot scheme into a district service is planned.

The development of diabetic shared care in Islington was supported by an Appeal Trust research fellowship to Dr B Hurwitz from the Rockefeller and endowments committee of the school of medicine, University College London. A development project grant from the British Diabetic Association and funds from the Greater London Enterprise Board of the GLC and the London Residuary Body supported this study. Annette Yiannaki, of the department of optometry and visual science, City University, interviewed all the optometrists. Rachel Pearce, of the clinical operational research unit, University College London, advised on data collection and performed much of the statistical analysis. We thank all the patients, general practitioners, and optometrists who participated.

1 Day JH, Humphreys SH, Alban-Davies H. Problems of comprehensive shared diabetes care. $B M \mathcal{F}$ 1987;294:1590-2.

2 Hayes TM, Harries J. Randomised controlled trial of routine hospital care versus routine general practice care for type II diabetics. BMF 1984;289: $728-30$.

3 Singh BM, Holland MR, Thorn PA. Metabolic control of diabetes in general practice clinics: comparison with a hospital clinic. BMF 1984;289:726-8.

Malins JM, Stuart JM. Diabetic clinic in a general practice. BMF 1971 ;iv: 161 .

5 Thorn PA, Russell RG. Diabetic clinics today and tomorrow: miniclinics in general practice. $B M \mathcal{F}$ 1973;ii:534-6.

6 Doney $\mathrm{BJ}$. An audit of the care of diabetes in a group practice. $f \mathrm{R}$ Coll Gen Pract 1976;26:734-42.
7 Hill RD. Community care service for diabetics in the Poole area. BMJ 1976;i:1137-9.

8 Dornan C, Fowler G, Mann JL, Markus A, Thorogood MA. A community study of diabetes in Oxfordshire. $7 \mathrm{R}$ Coll Gen Pract 1983;33:151-5.

9 Wilkes E, Lawton EE. The diabetic, the hospital and primary care. $f R$ Coll Gen Pract 1980;30:199-206.

10 Waine C. Why not care for your diabetic patients? London: Royal College of General Practitioners, 1986.

11 Tasker PRW. Is diabetes a disease for general practice? Practical Diabetes 1984;1:21-4.

12 Williams DRR, Munroe C, Hospedales CJ, Greenwood RH. A three-year evaluation of the quality of diabetes care in the Norwich community care scheme. Diabetic Med 1989;7:74-9.

13 Kopelman P, Keable-Elliott D. An inner city district diabetic care scheme. Diabetic Med 1990;8:558-61.

14 Burns-Cox CJ, Dean Hart JC. Screening of diabetics for retinopathy by ophthalmic opticians. BMf 1985;290:1052-4.

15 Hill RD. Screening for diabetic retinopathy at primary health care level. Diabetologia 1981;20:670.

16 Buxton MJ, Sculpher MJ, Ferguson BA, Humphreys JE, Altman JFB, Spiegelhalter DJ, et al. Screening for treatable diabetic retinopathy: comparison of different methods. Diabetic Med 1991;8:371-7.

17 Finlay R, Griffiths J, Johnson G, Law D. Can general practitioners screen their own patients for diabetic retinopathy? Health Trends 1991:23:104-5.

18 Sculpher MJ, Buxton MJ, Ferouson BA, Humphreys JE, Alman JFB, Spienter DJ, at. A rative costeffectiveness analysis of differB, Spiegelhalter DJ, et al. A relative cost-effectiveness analysis of differen

19 Rohan TE, Frost CD, Wald NJ. Prevention of blindness by screening for diabetic retinopathy: a quantitive assessment. BMF 1989;299:1198-201.

20 Kritzinger EE, Taylor KG. Diabetic eye disease, an illustrated guide to diagnosis and management. Lancaster: MTP Press, 1984.

21 Lindley DV, Scott WF. New Cambridge elementary statistical tables. Cambridge: Cambridge University Press, 1984:table 27.

22 Yiannaki A. Optometric screening for diabetic retinopathy in the community (BSc dissertation). London: Department of Optometry and Visual Science, City University, 1989:149, appendices.

23 Hammersley MS, Holland MR, Walford S, Thorn PA. What happens to defaulters from a diabetic clinic? $B M \mathcal{F} 1985 ; 291: 1330-2$.

24 Porter AMD. The Kirkcaldy community care project. Edinburgh: Department of General Practice, University of Edinburgh, 1979:75, appendices.

25 Kemple TJ, Hayter SR. Audit of diabetes in general practice. $B M \mathcal{F}$ $1991 \cdot 302: 451-3$.

26 Yudkin JS, Boucher BJ, Schopflin KE, Harris BJ, Clagg HR, Whyte NJD et al. The quality of diabetic care in a London health district. $f$ Epidemiol Community Health 1980;34:277-80.

27 Irving J, Casement S, Holme $Q$. A 'non-clinic' system of care for non-insulindependent diabetics in general practice. Practical Diabetes 1988;51:125-8.

28 Foulkes A, Kinmonth A, Frost S, MacDonald A. Organised personal care - an effective choice for managing diabetes in general practice. $\mathcal{F} R$ Coll Gen Pract 1989;39:444-7.

29 Haines A, Feder G. Guidance on guidelines. BMJ 1992;305:785-6.

(Accepted 22 December 1992)
University of Nottingham Medical School, Queen's Medical Centre,

Nottingham NG7 2UH

Mike Pringle, senior lecturer

in general practice

Carol Stewart-Evans,

research associate, department

of general practice

Carol Coupland, lecturer in

medical statistics, department

of public health medicine and epidemiology

Idris Williams, professor of

general practice

Simon Allison, consultant

physician, department of

medicine

Jennifer Sterland, research nurse, department of general practice

Correspondence to:

Dr Pringle.

BMF 1993;306:630-4

\title{
Influences on control in diabetes mellitus: patient, doctor, practice, or delivery of care?
}

\author{
Mike Pringle, Carol Stewart-Evans, Carol Coupland, Idris Williams, Simon Allison, \\ Jennifer Sterland
}

\section{Abstract}

Objective-To assess patient, doctor, practice, and process of care variables for their effect on glycaemic control in diabetes mellitus, and to quantify their relative effects.

Design-Search of general practice medical records, patient questionnaires and examination, doctor questionnaire, videotaping and analysis of consultations, and practice questionnaire.

Setting-12 practices with 32 participating general practitioners in Nottinghamshire.

Subjects-318 patients randomly selected from those with diabetes in each practice, 10 for each participating doctor.

Main outcome measure-Glycaemic control as measured by random glycated haemoglobin $A_{1 c}$ estimation (random haemoglobin $A_{1}$ measurement).

Results-Glycaemic control was significantly related to the disease process as measured by years since diagnosis, treatment group, and number of diabetes related clinical events. Females had significantly worse control than males. Other patient factors, such as age, social class, lifestyle, attitudes, satisfaction, and knowledge, had no association with glycaemic control. Of all the doctor factors examined, only doctors who professed a special interest in diabetes achieved significantly better glycaemic control. Bigger and better equipped practices and those with a diabetic miniclinic had patients with significantly better glycaemic control, as did those with access to dietetic advice. Patients attending hospital clinics had worse glycaemic control, but this seemed to be attributable to the case mix and practice characteristics. Shared care did not contribute to the multiple linear regression model.

Conclusion-Glycaemic control among diabetic patients in the community is related to such factors as treatment group, sex, and years since diagnosis; it is also related to the organisation and process of care. The findings support concentrating diabetic care on partners with special interests in diabetes in well equipped practices with adequate dietetic support.

\section{Introduction}

The age adjusted prevalence of diagnosed diabetes mellitus is between $1.01 \%$ and $1.04 \%^{2}$ in white people in the United Kingdom, with higher rates among some ethnic minorities. ${ }^{3}$ There is evidence that good 